\title{
Nutritional Status and Associated Factors Among Children 6-59 months Who Attend IMNCI Departments in Bole Sub City Health Centers, Addis Ababa, Ethiopia, 2021
}

Lelisa Worku ( $\square$ lalisaworku@gmail.com )

Rift Valley University

Tesfaye Bulcha

Rift Valley University

Addisu Taddesse

Sisay Hailu

Rift Valley University

Tadele Geletu

Rift Valley University

Mintesinot Taddesse

Rift Valley University

\section{Research Article}

Keywords: Nutritional status, children, 6-59 months, undernutrition

Posted Date: August 23rd, 2021

DOl: https://doi.org/10.21203/rs.3.rs-831041/v1

License: (c) (i) This work is licensed under a Creative Commons Attribution 4.0 International License. Read Full License 


\section{Abstract}

Background: Globally, 52 million children under 5-years of age were wasted and 155 million are stunted, while 41 million are overweight/obese. However, the contemporary rate of tumbling malnutrition is not fast ample to reach the World Health Organization global target for dropping malnutrition by $40 \%$ by 2025. Hence aimed to assess nutritional status and associated factors among under-five children IMNCl departments in the Bole Sub City Health centers, Addis Ababa, Ethiopia.

Methods: The study was conducted in the Bole sub-city at selected health centers through a crosssectional study design. 385 Sample were selected by simple random sampling. Data were collected through a face-to-face interview. Statistical Package for Social Science (SPSS) software version 25 was used for analysis. Descriptive statistics were used to describe the characteristics of the study population. Binomial and multinomial logistic regression was fitted to identify factors associated with undernutrition.

Result: The magnitude of normal nutrition was $69.6 \%$, overweight/obese $3.2 \%$, and undernutrition $27.2 \%$. Obese mothers increasing odd over nutrition ( $A O R=9.13$, at $95 \%, \mathrm{Cl}: 1.05-79.79)$. While, having counseling about child nutrition ( $\mathrm{AOR}=18.37$, at $95 \% \mathrm{Cl}$ : 4.06-83.08), who feed children (AOR=6.43, 95\% Cl: 1.1137.43 ) and growth monitoring ( $\mathrm{AOR}=0.50$, at $95 \%, \mathrm{Cl}$ : 0.26-0.98) were statistically associated with undernutrition.

Conclusion: The magnitude of normal nutrition was higher than both under-nutrition and obese/overweight. However, the magnitude of undernutrition chiefly stunting was remained high. Obese mothers, having counseling on nutrition, who feed children, and growth monitoring were statistically associated with nutritional status.

\section{Introduction}

Adequate dietary intake is critically important for the child to obtain good nutritional status(1). Malnutrition abnormality of nutritional status which incorporated undernutrition and overnutrition(2).

Malnutrition among children below 5 years is a recognized problem worldwide and more so in subSaharan Africa(3). Malnutrition, in all its forms, includes undernutrition (wasting, stunting, underweight), overweight, obesity, and resulting diet-related no communicable diseases(2). Globally, 52 million children under 5 years of age are wasted, 17 million are severely wasted and 155 million are stunted, while 41 million are overweight or obese(4). The evidence indicated about nearly half (45\%) under-five children's death and $11 \%$ of global disease burden are related to undernutrition (4).

Childhood obesity is associated with a greater risk for the development of several adverse health and psychosocial outcomes across the life span(5) and is a major risk factor for childhood noncommunicable diseases (NCD), in particular, cardiovascular diseases(6). 
Correspondingly, malnutrition results in increased incidence, severity, and case fatality of common infections, risks continue beyond acute episodes resulting in significant post-discharge mortality and both were in a vicious cycle (7). Therefore, The synergism between malnutrition and infection contributes substantially to childhood morbidity and mortality(8).

Malnutrition tended to produce notable morphological changes in the brain which damage the intellectual potential and leads to reduced brain size, inferred from measurements of head circumference $(\mathrm{HC})(9)$

Undernutrition is the most dominant form of malnutrition among children in developing countries(10). Sub-Saharan Africa has one of the highest levels of child malnutrition globally(11). For instance, Burundi record the highest prevalence of stunting (57.7\%), Niger highest report of wasting(18\%), again Burundi(28.8\%) and Ethiopia(25.2\%) report the highest prevalence of underweight(11). Undernutrition imposes significant costs on the Ethiopian economy as well as impacting the well-being of the $\operatorname{society}(12)$.

In Ethiopia, the prevalence of stunting decreased from 47\% in 2005 to $39 \%$ in 2016, but the prevalence of wasting changed little over the same period (only reduced by 1\%)(13). Malnutrition of under-five children in Ethiopia in the form of stunting, underweight, and wasting were as $44 \%, 29 \%$, and $10 \%$ and Oromia national region state $44.1 \%, 39.6 \%$, and $12.5 \%$, respectively (14).

However, the current magnitude of malnutrition lessening is not fast enough to reach the World Health Organization global target for dropping malnutrition by $40 \%$ by 2025 . Likewise, there is a lack of deliberation in the case of overnutrition since lacking policy that addresses overnutrition as in the Ethiopian context. Therefore, this study aimed to assess nutritional status and associated factors among under-five children IMNCI departments in Bole Sub City Health centers.

\section{Methods And Materials}

\subsection{Study area and period}

The study was conducted from February 10/2021 to July 15/2021 at bole sub city's selected health centers, those are Gerji, Bole17, and Bole17/20, and Bulbula health centers. Gerji health center is serving an estimated total population of 51,768 among them 3,683 of them are estimated under-five children. While Bole17/20 health center is for the total population of 51,199 and 3,542 under-five children. Similarly, Bole17 serves a total population of 49476 and 3415 under-five children, while Bulbula Health center is for 26682 population and out of 2232 expected to under five age children. All health centers are found in the Bole sub-city, Bole sub-city is one of the sub-cities found in Addis Ababa at the southeast of the city. (Information was taken from those selected health centers).

\subsection{Study design}


A facility-based cross-sectional study design was employed to conduct this study.

\subsection{Population}

\subsubsection{Source of population}

All children age 6-59 months attending IMNCI service at Gerji, Bole17, Bole17/20, and Bulbula Health Centers.

\subsubsection{Study population}

Eligible children aged 6-59 months attending IMNCI service at Gerji, Bole17, Bole17/20, and Bulbula Health Centers and those come to a health facility during data collection.

\subsubsection{Eligibility criteria}

\subsubsection{Inclusion criteria}

1. The children aged 6-59 months who came to health centers during the data collection period.

\subsubsection{Exclusion criteria}

1. The children with anatomically impaired and difficulty taking anthropometric measurements.

2. Severely ill children.

3. Chronically ill children and bedridden for a long time.

4. The children are known as undernutrition and enrolled in nutritional treatment.

\subsection{Sample size determination}

Sample size calculation for the first specific objective was calculated by single population proportion formula. $Z$ value at $95 \% \mathrm{Cl}$ was used which 1.96 and $5 \%$ margin of error is considered. Population proportion was taken from a study conducted in Addis Ababa, Addis Ketema sub-city, The prevalence of stunting, wasting, and underweight were $35.1 \%, 4.7 \%$, and $12.0 \%$ respectively $(25)$. While the magnitude of obese/overweight was taken from other study conducted in Ethiopia which was 1.99\%

For stunting proportion taken from the study was 0.351

$\mathrm{n}=(\underline{\mathrm{Za} / 2}) \underline{{ }^{2} \mathrm{P}}(\underline{1-} \underline{\mathrm{p}})$ 
$\mathrm{n}=(\underline{1.96})^{2} 0.351(\underline{1-0.351})$.

$(0.05)^{2}$

$\mathrm{n}=\underline{350}$

By using the above formula, the sample size obtained by wasting was 69 , by underweight 81 , and obese/overweight 30.

But there was no evidence whether the sample size calculated for the magnitude of nutritional status was working for associated factors or not.

Therefore, the sample size for associated factors was calculated by using epi launch info version 7.2.4. The proportions were taken from a study conducted in Addis Ababa and the determined samples were presented (Table 1).

One to one ratio, $80 \%$ power $(1-\beta)$, and $95 \% \mathrm{Cl}$ are used to compute the sample.

Our largest sample size was 350 and when 10\% non-response was added it yields a total sample size of 385.

\subsection{Sampling Method}

The sample was taken by simple random sampling from each health center. According to the estimation of children who follow to health center averagely, 10 children came to each health center and 40 in aggregation every day. This means in twenty days more than 800 children came to four health centers. Therefore, nearly half of the children were selected by lottery method to meet the sample size (figure 2).

\subsection{Variables}

\subsubsection{Dependent variables}

1. Nutritional status (undernutrition, overnutrition, and normal nutrition).

\subsubsection{Independent}

Socio-demographic and socio-economic factors

1. Age of child

2. Sex of child 

3. Education of mother
4. Income
5. Occupation of mother
6. Family size
7. Age of mother
8. Occupation of father

\section{Feeding practice and dietary related}

1. Complementary feed

2. Dietary diversity

3. Sweaty food

4. Breastfeeding

5. Fortified food

6. Eating on a separate dish

7. Meal amount \& frequency

8. Who feed?

9. Snack between meal

\section{Maternal and child health service utilization}

1. Immunization

2. child health

3. vitamin $\mathrm{A}$

4. growth monitoring

5. obese/ overweight mother

6. Deworming

7. having counseling

\section{Hygiene and environmental factors}
1. Latrine
2. Handwashing
3. Food hygiene.

\subsection{Operational definition}

Low dietary diversity: when consuming only less than or equal to three among seven types of food(15). 
Minimum dietary diversity: when consuming at least four types of food among seven types of food(15).

Obese: Children with z-scores of greater than 3 standard deviations (SDs) for WFH by Anthro plus software measurement

Overnutrition: Children with z-scores greater than 2 standard deviations (SDs) for WFH by Anthro plus software measurement

Overweight: Children with z-scores in between 2-3 standard deviations (SDs) for WFH by Anthro plus software measurement

Stunting: Children with z-scores of less than -2 standard deviations (SDs) for HFA by Anthro plus software measurement(16)

Undernutrition: Children with at least one or more measurements z-scores of less than -2 standard deviations (SDs) of WFH, WFA, and HFA by Anthro plus software measurements(16) Underweight: Children with z-scores of less than -2 standard deviations (SDs) for WFA by Anthro plus software measurement(16).

Wasting: Children with z-scores of less than -2 standard deviations (SDs) for WFH by Anthro plus software measurement(16).

\subsection{Data collection methods and tools}

Data were collected through a face-to-face interview by structured questionnaires and anthropometric measurements were taken as well. The structured questionnaires that were used to measure the dietary condition of the children were adopted from (FANTA) while other questionnaires were prepared. All questionnaires were originally prepared in English and translated to the Amharic language by a language professional. The new questionnaires were pretested on $5 \%$ hospital pre-data collection. Data were collected by five trained clinical nurse those previously had an experience on data collection. The principal investigator was to control the overall work of data collectors.

The length of children aged from 6 to 24 years old or cannot standing upright was measured using a horizontal wooden length board in a recumbent position and read to the nearest $0.1 \mathrm{~cm}$ while the

The height of children above two years old was measured stadiometer scale without shoes. Child weight was measured to the nearest $0.1 \mathrm{~kg}$ by beam balance. Weight was taken with light clothing and no shoes. Instrument calibration was done before weighing each child. To check edema, normal thumb pressure was applied on both feet for three seconds. The data collectors were checked whether a shallow print was remained on either foot or not when the thumb was lifted. The data of anthropometric measurements were inserted into standardized WHO Anthro software version 3.2.2 to calculate the $Z$ value of HFA, WFH, and WFA. 


\subsection{Data quality control}

All questionnaires were translated to the local language (Amharic) for more clarity for both data collectors and respondents. Pre-training was given for data collectors on how to collecting data, recording, the principle of research ethics, and how to take anthropometric measurements. Pretest was done on $5 \%$ of respondents for new questions but no confusion or unfitness happen. The weighing scale was checked daily against the standard weight for accuracy. Beam balance was set to zero for every measurement.

\subsection{Data processing and analysis}

Data were checked for completeness and consistencies and then it was cleaned, coded, and entered using Epidata 3.1 and exported to the Statistical Package for Social Science (SPSS) software version 25 for analysis. Anthropometric measurements were entered into WHO Anthro plus individually to calculate the Z-value of (HFA, WFH, and WFA). Descriptive statistics will be used to describe the study population about relevant variables.

Logistic regression was fitted to identify the association between dependent (nutritional status) and independent variables. The analysis was conducted to select candidate variables to the initial multinomial model. Those variables that show association with nutritional status (overnutrition and undernutrition) at a p-value less than 0.25 were included in an initial multinomial logistic regression model.

Both crude and adjusted odds ratios with their corresponding 95\% confidence interval were used to determine the strength of association. Assumptions of logistic regression were checked before final multinomial analysis using probability Bi variable graph and collinearity diagnostics like Variance inflation factor and correlation matrix.

The final multinomial model goodness of fit was checked using classification table percentage, chisquare test, and log-likelihood chi-square test. A p-value of less than 0.5 was used to declare the statistical significance of the finding in this study. The results were presented using sentences, tabular, and graphs based on the types of data.

\subsection{Ethical consideration}

Ethical clearance was taken from Rift Valley University, permission letter was also taken from Addis Ababa City public health institute and emergence control office and management office of Bole sub-city health office. Inform consents were done with mothers or caregivers of the children. The right of refusal or withdrawal was respected. The data was kept confidential. 


\section{Results}

\subsection{Socio-demographic and socio-economic factors of respondents}

Out of 385 candidates, $372(96.6 \%)$ of them were participating in this study The mean age of children was $22.76 \pm 14.78$ ( $95 \%, \mathrm{Cl}: 21.26$ to 24.27$)$ months and the mean age of mothers was $27.38 \pm 3.75$ ages. The majority of children were female and most of the family had two or one child. Two hundred forty-five $(65.9 \%)$ were housewives while one hundred sixty-three (43.8\%) of a father were working private work. $250(67.2 \%)$ of mothers/caregivers had counseling or information about the nutrition of children (Table 2).

\subsection{Maternal and child health services related factors}

Ninety-seven (26.1\%) of children have had a recent history of disease in which most of them had diarrhea [56 (57.7\%)]. One hundred thirty-five (36.5\%) were vitamin A and two hundred thirty-three (62.6\%) of them were received deworming during the past six months. Two hundred sixty-seven (71.8\%) of children were held under a growth monitoring program. Twenty-seven (7.3\%) of mothers were obese or overweight (Table 3).

\subsection{Feeding practice and dietary related factors}

The majority of mothers/caregivers were appropriate complementary feed their children [225 (60.5\%)]. While $240(64.5 \%)$ of children scored high in dietary diversity. The majority $(66.1 \%)$ of children were either currently breastfeeding or meet optimum breastfeeding. The majority of mothers/caregivers were given snuck between meals for their children [390(83.1\%)]. Two hundred thirty-nine (64.2\%) of children were fed their meal in a separate dish. One hundred thirty-three (35.8\%) of children were mostly fed food prepared in the industry (Table 4).

\subsection{Hygiene and environment-related factors}

All caregivers/mother washed their hands but only 127(34.1\%) of them were used soap for handwashing. Majority of mother/caregiver were feeding their children by as soon as prepared food. All most of the families use the standardized type of latrine [366(98.4)] (Table 5).

\subsection{Overall magnitude of nutritional status among children attending IMNCI at selected health centers}

The magnitude of nutritional status includes normal nutrition 69.6\% (259) (95\%, Cl: 64.7\%-74.1\%), over weight/obese $12(3.2 \%)$ (95\%, Cl: $1.84 \%$ to $5.60 \%)$ out of them and $4(1.1 \%)(95 \%, \mathrm{Cl}: 0.4 \%$ to $2.84 \%)$ 
obese.

Magnitude of under nutrition was $27.2 \%$ (101) (95\%, Cl: $22.85 \%$ to $31.92 \%)$ which include magnitude of stunting $26.9 \%$ (100) (95\%, Cl: $22.6 \%$ to $31.6 \%)$, underweight $13.2 \%(49)(95 \%, \mathrm{Cl}: 10.08 \%$ to $17.02 \%)$ and wasting $5.1 \%$ (19) $(95 \%$, Cl: 3.27 to $7.88 \%)$ (Figure 4).

\subsection{Factors associated with nutritional status}

Binomial logistic regression was conducted to selecting candidate variables for multinomial regression. Having nutritional counseling or information, food prepared in-home/industry, feeding child on a separate dish, consuming more sweaty food, occupation of mother, who feeding children, growth monitoring, overweight or obese mother and breastfeeding were had $p$-value $<0.25$ and candidate for multinomial logistics regression.

Model fitness and classification table percentage were checked. Then multinomial logistic regression was employed for candidate variables. After multinomial logistic regression, obese/overweight mothers, having nutritional counseling/information, growth monitoring, and who feed child had a statistically significant association with nutritional status at $p$-value $<0.05$.

Based on finding children from obese mothers were 9.13 times more likely to develop over nutrition as compared with those not from obese mothers (AOR=9.13, at 95\%, Cl: 1.05-79.79). Children from not counseled mothers/caregivers or informed about child nutrition were 18.37 times more likely to develop undernutrition as compared with those who were counseled or informed (AOR=18.37, at 95\% Cl: 4.0683.08). Likewise, children who feed by caregiver were 6.43 times more developed undernutrition as compared with those feed by their mother (AOR=6.43, 95\% Cl: 1.11-37.43). similarly, children who followed undergrowth monitoring programs were less likely to be undernutrition as compared with those who did not follow (AOR $=0.50$, at $95 \%$, Cl: $0.26-0.98$ ).

\section{Discussion}

The finding of the study revealed the magnitude of overnutrition was $3.2 \%(95 \%$, Cl: $1.84 \%$ to $5.60 \%)$ which is in line with evidence-based findings conducted in Ethiopia (1.99\%) (23). But it's lower than the study conducted in Ho Chi Minh City, Vietnam (25.8\%) (19), a study conducted in Cameroon (8\%)(20), the study conducted in the Middle East and North Africa (MENA) and Latin America and the Caribbean (10\%) (21).The variation might be due to dietary patterns and the socio-demographic difference between study areas. Our finding of overweight/obese was slightly greater than a study conducted in Nigeria (1.5\%) (22). The incongruity might be due to sampling size, methodological approach, and sociodemographic variation.

The finding of study revealed of undernutrition was $27.2 \%$ (95\%, Cl: $22.85 \%$ to $31.92 \%)$ which include magnitude of stunting $26.9 \%$ (95\%, Cl: $22.6 \%$ to $31.6 \%$ ), underweight $13.2 \%$ (95\%, Cl: 10.08 to 17.02$)$ and 
wasting $5.1 \%$ (95\%, Cl: 3.27 to $7.88 \%)$. Based on our finding, the magnitude of stunting was slightly lower than study conducted in sera Lanka (36.4\%) East of Ethiopia (36.07\%) (24), another study recently on the orphan center of Ethiopia (34.8\%) (25), a study conducted Somali region (26) $33.4 \%$ and a study conducted in the Maldives (32.4\%)(1). The disparity might be due to increment health service quality or due to socio-demographic and socio-economic variation.

The finding of our study showed the magnitude of underweight was $13.2 \%$ ( $95 \%$, Cl: $10.08 \%$ to $17.02 \%)$, which was in line with the study conducted in Addis Ababa 12\% (25) and the study conducted in the Sodo district (14\%) (29). However, it is lower than the study conducted in the Maldives (24.6\%) (1), in Haramaya (23\%) (24), and Bule Hora district (29.9\%) (27). The variation may be due to differences in socio-economic and accessibility of information.

Correspondingly, the finding indicated the magnitude of wasting was $5.1 \%(95 \%, \mathrm{Cl}$ : 3.27 to $7.88 \%)$. This is in line with a study recently conducted in orphan children of Addis Ababa $4.7 \%$ (25). But lower than study conducted Maldives 16.3\% (1), a study conducted in Bule Hora (13.4\%) (27), report of a study conducted Sodo zuria district 11\% (29) and other study conducted in Ethiopia 12.09\% (30).

According to our finding obese/overweight were positively associated with overweight that increases odd of overweight or obese by nine times. Our finding was inconsistent with a study conducted in Cameroon (20). However, there is no evidence for the reason of relationship between maternal obesity/overweight and children obese/overweight wither genetic or eating pattern of the family.

Similarly, having counseling or information about nutrition was found to be negatively associated with undernutrition. Nutrition counseling is a combination of communication and nutrition expertise and also psychological skills delivered by trained nutrition (42). According to our findings, children from mothers who had not been counseled were 18 times more likely to develop undernutrition as compared with those who had. Which is inconsistent with a study conducted in Bangladesh (37), and another study (38).

The finding of the study indicated feeding by mother reducing odd of undernutrition and feeding by caregiver increasing odd of undernutrition as compared with mother. Which was inconsistent with a study which stated Children feeding practice done by mother were effective which is resulting for improvement of nutritional status (35). Nevertheless, it has disagreed with the study conducted in Indonesia which said there were no significant associations between the role and knowledge of the mothers and adequate nutritional status of their infants and toddlers (36). The disparity might be due to methodological discrepancy and variation in culture.

Growth monitoring is important to program for following nutritional status from time to time. In this study, growth monitoring was decreasing the odd of undernutrition. Nonetheless, this variable was not addressed by many studies.

\section{Conclusion And Recommendation}




\subsection{Conclusion}

The magnitude of normal nutrition was higher than both undernutrition and obesity/overweight. However, the magnitude of undernutrition predominantly stunting was remained high. Obese mothers, having counseling on nutrition, who feed children and growth monitoring were statistically associated with nutritional status (malnutrition).

\section{2 recommendation}

1. Appropriate counseling and training shall be needed for both caregiver and mother to increasing behavior of children feeding practice by health care providers.

2. The family should be emphasized the nutrition of their children and share positive advice for the caregiver.

3. Vital strategy, policy, and planning shall be suggested to the government (policy-maker) by considering other studies for both overnutrition and undernutrition.

4. Fruitful investigations shall be recommended for researchers by including a more advancing method of approach.

5. Education and training shall be better if they considering give special consideration on study related to children and further giving training for health care provider and mother.

\section{Declarations}

\section{Acknowledgments}

Our gratitude goes to all data collectors, mothers/caregivers who give their time to respond to all important questions, Selected health center's administrative and staff for their contribution.

\section{Abbreviations}

H/A Height for Age

$\mathrm{H} / \mathrm{C} \quad$ Health Center

HFA Height for Age

IMNCI Integrated Management Neonatal and Child Illness

SPSS Statistical Package for Social Sciences

WFA Weight for Age

WFH Weight for Height 


\section{References}

1. Ul Haq I, Asra M, Tian Q, Ahmed B, Khan N, Ahmad Ml, et al. Association of infant and child feeding index with undernutrition in children aged 6-59 months: A cross-sectional study in the Maldives. Am J Trop Med Hyg. 2020;

2. World Health Organization. WHO - Malnutrition. www.who.int. 2018.

3. Tshiya Y, Magoha H. Prevalence and Risk Factors of Malnutrition among Children of Ages 6 to 59 Months in Manyovu, Buhigwe District Kigoma-Tanzania. J Food Nutr Res. 2020;

4. World Health Organisation (WHO). Fact Sheets: Malnutrition. Fact Sheets Malnutrition. 2020;

5. Mrema JD, Elisaria E, Mwanri AW, Nyaruhucha CM. Prevalence and Determinants of Undernutrition among 6- To 59-Months-Old Children in Lowland and Highland Areas in Kilosa District, Tanzania: A CrossSectional Study. J Nutr Metab. 2021;

6. Akombi BJ, Agho KE, Merom D, Renzaho AM, Hall JJ. Child malnutrition in sub-Saharan Africa: A meta-analysis of demographic and health surveys (2006-2016). PLoS One. 2017;

7. Amare ZY, Ahmed ME, Mehari AB. Determinants of nutritional status among children under age 5 in Ethiopia: Further analysis of the 2016 Ethiopia demographic and health survey. Global Health. 2019;

8. Kassa ZY, Behailu T, Mekonnen A, Teshome M, Yeshitila S. Malnutrition and associated factors among under-five children (6-59 Months) At Shashemene Referral Hospital, West Arsi Zone, Oromia, Ethiopia. Curr Pediatr Res. 2017;

9. Seid A, Seyoum B, Mesfin F. Determinants of Acute Malnutrition among Children Aged 6-59 Months in Public Health Facilities of Pastoralist Community, Afar Region, Northeast Ethiopia: A Case-Control Study. J Nutr Metab. 2017;

10. Warnick JL, Pinto S, Ding K, Janicke DM. Childhood obesity. In: Adherence and Self-Management in Pediatric Populations. 2020.

11. Noutakdie Tochie J, Mbonda A, Fonkwo V, Aletum V. Childhood Overweight and Obesity in SubSaharan Africa: Current Definition, Prevalence and Risk Factors. Acta Sci Paediatr. 2019;

12. Pravana NK, Piryani S, Chaurasiya SP, Kawan R, Thapa RK, Shrestha S. Determinants of severe acute malnutrition among children under 5 years of age in Nepal: A community-based case-control study. BMJ Open. 2017; 
13. Walson JL, Berkley JA. The impact of malnutrition on childhood infections. Current Opinion in Infectious Diseases. 2018.

14. Ibrahim MK, Zambruni M, Melby CL, Melby PC. Impact of childhood malnutrition on host defense and infection. Clinical Microbiology Reviews. 2017.

15. Tiwari K, Goyal S, Malvia S, Sanadhya A, Suman RL, Jain R. Impact of malnutrition on head size and development quotient. Int J Res Med Sci. 2017;

16. Tut G, Tsegaye D. <p>Determinants of Acute Malnutrition Among Children Aged 6-59 Months Visiting Public Health Facilities in Gambella Town, Southwest Ethiopia: Unmatched Case-Control Study $</ p>$. Nutr Diet Suppl. 2020;

17. Pandey S, Gaur A, Singh A, Kassere S. IMPACT OF CHILD FEEDING PRACTICES ON NUTRITIONAL STATUS OF CHILDREN IN UTTARAKHAND. Int J Med Biomed Stud. 2019;

18. Weihrauch-Blüher S, Schwarz P, Klusmann JH. Childhood obesity: increased risk for cardiometabolic disease and cancer in adulthood. Metabolism. 2019;

19. Huynh G, Huynh QHN, Nguyen NHT, Do QT, Khanh Tran V. Malnutrition among 6-59-Month-Old Children at District 2 Hospital, Ho Chi Minh City, Vietnam: Prevalence and Associated Factors. Biomed Res Int. 2019;

20. Tchoubi S, Sobngwi-Tambekou J, Noubiap JJN, Asangbeh SL, Nkoum BA, Sobngwi E. Prevalence and risk factors of overweight and obesity among children aged 6-59 months in Cameroon: A multistage, stratified cluster sampling nationwide survey. PLoS One. 2015;

21. Ghattas H, Acharya $Y$, Jamaluddine Z, Assi M, El Asmar K, Jones AD. Child-level double burden of malnutrition in the MENA and LAC regions: Prevalence and social determinants. Matern Child Nutr. 2020;

22. Okari T, Nte A, Frank-Briggs A. Prevalence of malnutrition among under-fives in Okrika Town, Nigeria. IOSR J Dent Med Sci e-ISSN. 2019;

23. Farah AM, Nour TY, Endris BS, Gebreyesus SH. Concurrence of stunting and overweight/ obesity among children: Evidence from Ethiopia. PLoS One. 2021;

24. Redi F, Egata G, Kedir A. Prevalence of Malnutrition among Children Aged 6-59 in Haramaya District, Oromia, Ethiopia. J Biom Biostat. 2017;

25. Teferi $\mathrm{H}$, Tessema T. Magnitude and Associated Factors of Undernutrition Among Children Aged 659 Months in Ethiopian Orphanage Centres. Pediatr Heal Med Ther. 2021;

26. Ma'Alin A, Birhanu D, Melaku S, Tolossa D, Mohammed Y, Gebremicheal K. Magnitude and factors associated with malnutrition in children 6-59 months of age in Shinille Woreda, Ethiopian Somali regional 
state: A cross-sectional study. BMC Nutr. 2016;

27. Asfaw M, Wondaferash M, Taha M, Dube L. Prevalence of undernutrition and associated factors among children aged between six to fifty nine months in Bule Hora district, South Ethiopia. BMC Public Health. 2015;

28. Roba AA, Assefa N, Dessie Y, Tolera A, Teji K, Elena H, et al. Prevalence and determinants of concurrent wasting and stunting and other indicators of malnutrition among children 6-59 months old in Kersa, Ethiopia. Matern Child Nutr. 2021;

29. Tufa EG, Dake SK, Bekru ET, Tekle HA, Bobe TM, Angore BN, et al. Magnitude of wasting and underweight among children 6-59 months of age in Sodo Zuria District, South Ethiopia: A community based cross-sectional study. BMC Res Notes. 2018;

30. Kassie GW, Workie DL. Exploring the association of anthropometric indicators for under-five children in Ethiopia. BMC Public Health. 2019;

31. Mrema JD, Elisaria E, Mwanri AW, Nyaruhucha CM. Prevalence and Determinants of Undernutrition among 6- to 59-Months-Old Children in Lowland and Highland Areas in Kilosa District, Tanzania: A CrossSectional Study. J Nutr Metab. 2021;

32. Sand A, Kumar R, Shaikh BT, Somrongthong R, Hafeez A, Rai D. Determinants of severe acute malnutrition among children under five years in a rural remote setting: A hospital based study from district Tharparkar-Sindh, Pakistan. Pakistan J Med Sci. 2018;

33. Hossain A, Niroula B, Duwal S, Ahmed S, Kibria MG. Maternal profiles and social determinants of severe acute malnutrition among children under-five years of age: A case-control study in Nepal. Heliyon. 2020;

34. Samarasekara GS, Mettananda S, Punchihewa P. Analysis of nutritional status and factors associated with undernutrition in children aged 6-59 months in a rural area of Sri Lanka. Sri Lanka J Child Heal. 2019;

35. Keaulana S, Antonio M, Schoch H, Banna J. A Literature Review of the Role of Mindfulness Practices in Nutrition for Mothers and Their Children. American Journal of Lifestyle Medicine. 2019.

36. Hasibuan Y, Batubara A, Suryani S. Mother's Role and Knowledge in Young Children Feeding Practices on the Nutritional Status of Infant and Toddler. Glob J Health Sci. 2019;

37. Mistry SK, Hossain MB, Arora A. Maternal nutrition counselling is associated with reduced stunting prevalence and improved feeding practices in early childhood: A post-program comparison study. Nutr J. 2019; 
38. Nsiah-Asamoah C, Pereko KKA, Intiful FD. Nutritional counselling interactions between health workers and caregivers of children under two years: Observations at selected child welfare clinics in Ghana. BMC Health Serv Res. 2019;

39. Rose ES, Blevins M, González-Calvo L, Ndatimana E, Green AF, Lopez M, et al. Determinants of undernutrition among children aged 6 to 59 months in rural Zambézia Province, Mozambique: Results of two population-based serial cross-sectional surveys. BMC Nutr. 2015;

40. Woldegebriel AG, Desta AA, Gebreegziabiher G, Berhe AA, Ajemu KF, Woldearegay TW. Dietary Diversity and Associated Factors among Children Aged 6-59 Months in Ethiopia: Analysis of Ethiopian Demographic and Health Survey 2016 (EDHS 2016). Int J Pediatr. 2020;

41. Beyene S, Willis MS, Mamo M, Legesse B, Regassa T, Tadesse T, et al. Nutritional status of children aged 0-60 months in two drought-prone areas of Ethiopia. South African J Clin Nutr. 2020;

42. Pradana R, Hidayatullah P, Susi N, Asih W, Kep M, Cahya N, et al. RELATIONSHIP BETWEEN NUTRITION COUNSELING WITH STUNTING EVENTS IN VILLAGE CUMEDAK, SUMBERJAMBE, JEMBER Oleh. Repository UnmuhjemberAcld. 2020;

\section{Tables}

Table 1: sample size determination for associated factors, children age 6-59 months attend IMNCl at Bole Sub-city health centers, Addis Ababa Ethiopia, 2021

\begin{tabular}{lllll} 
Variables & $\begin{array}{l}\text { Proportion of } \\
\text { exposed }\end{array}$ & $\begin{array}{l}\text { Proportion of } \\
\text { unexposed }\end{array}$ & OR & $\begin{array}{l}\text { Sample with 10\% non- } \\
\text { response }\end{array}$ \\
\hline $\begin{array}{l}\text { Government } \\
\text { workers }\end{array}$ & 0.022 & 0.169 & 0.1 & 165 \\
\hline $\begin{array}{l}\text { Feeding } 4-5 \\
\text { times }\end{array}$ & 0.039 & 0.304 & 0.09 & 84 \\
\hline First child & 0.027 & 0.191 & 0.12 & 150 \\
\hline $\begin{array}{l}\text { One child in } \\
\text { home }\end{array}$ & 0.094 & 0.613 & 0.06 & 35 \\
\hline Diarrhea & 0.122 & 0.784 & 0.03 & 24
\end{tabular}

Table 2: Socio-demographic and socio-economic factors of Family/children age 6-59 months attend health service attend IMNCI at Bole sub-city selected health centers, Addis Ababa, Ethiopia, 2021 


\begin{tabular}{|c|c|c|c|}
\hline Variables & Alternatives & Frequency & Percent \\
\hline \multirow[t]{3}{*}{ Age of children } & 6-11 months & 114 & 30.6 \\
\hline & $12-23$ months & 110 & 29.6 \\
\hline & 24-59 months & 148 & 39.8 \\
\hline \multirow[t]{2}{*}{ Sex of respondents } & Male & 159 & 42.7 \\
\hline & Female & 213 & 57.3 \\
\hline \multirow[t]{2}{*}{ Number of children } & Two or one & 230 & 61.8 \\
\hline & Above two & 142 & 38.2 \\
\hline \multirow[t]{2}{*}{ Educational status of Mother } & No formal education & 46 & 12.4 \\
\hline & $\begin{array}{l}\text { Have formal } \\
\text { education }\end{array}$ & 326 & 87.6 \\
\hline \multirow[t]{2}{*}{ Occupation of Mother } & House wife & 245 & 65.9 \\
\hline & Outside work & 127 & 34.1 \\
\hline \multirow[t]{3}{*}{ Occupation of Father } & Job seeker & 59 & 15.9 \\
\hline & Government & 150 & 40.3 \\
\hline & Private & 163 & 43.8 \\
\hline \multirow[t]{3}{*}{ Marital status of mother } & Single & 8 & 2.2 \\
\hline & Divorced & 15 & 4 \\
\hline & Married & 349 & 93.8 \\
\hline \multirow{2}{*}{$\begin{array}{l}\text { Have counselling or information about nutritional } \\
\text { status }\end{array}$} & Yes & 250 & 67.2 \\
\hline & No & 122 & 32.8 \\
\hline
\end{tabular}

Table 3: Maternal and child health service of children age 6-59 months attend health service attend IMNCl at Bole sub-city selected health centers, Addis Ababa, Ethiopia, 2021 


\begin{tabular}{llll} 
Variables & Alternatives & Frequency & Percent \\
\hline Sick child & Yes & 97 & 26.1 \\
\cline { 2 - 4 } & No & 275 & 73.9 \\
\hline Disease type & Diarrhea & 56 & 57.7 \\
\cline { 2 - 4 } & Cough & 28 & 28.9 \\
\cline { 2 - 4 } & Fever & 10 & 11.3 \\
\cline { 2 - 4 } & Other & 2 & 2.1 \\
\hline Receive vitamin A supplement & Yes & 135 & 36.3 \\
\cline { 2 - 4 } & No & 237 & 63.7 \\
\hline Immunization status & Not full & 126 & 33.9 \\
\cline { 2 - 4 } & Fully vaccinated & 246 & 66.1 \\
\hline Growth monitoring & Yes & 267 & 71.8 \\
\cline { 2 - 4 } & No & 105 & 28.2 \\
\hline Deworming & Yes & 233 & 62.6 \\
\cline { 2 - 4 } & No & 139 & 37.4 \\
\hline Obese or overweight mother & yes & 27 & 7.3 \\
\cline { 2 - 4 } & No & 241 & 91.7 \\
\hline
\end{tabular}

Table 4: Feeding practice and dietary related factors of children age 6-59 months attend health service attend IMNCl at Bole sub-city selected health centers, Addis Ababa, Ethiopia, 2021. 


\begin{tabular}{|c|c|c|c|}
\hline Variables & Alternatives & Frequency & Percent \\
\hline \multirow[t]{2}{*}{ Complementary feeding } & Appropriate & 225 & 60.5 \\
\hline & Not appropriate & 147 & 39.5 \\
\hline \multirow[t]{2}{*}{ Dietary diversity } & Lower & 132 & 35.5 \\
\hline & Higher & 240 & 64.5 \\
\hline \multirow[t]{2}{*}{ Meal frequency } & Two or less & 126 & 33.9 \\
\hline & Three and above & 246 & 66.1 \\
\hline \multirow[t]{3}{*}{ Amount of meal estimation } & Half or less & 11 & 3 \\
\hline & $1 / 2$ to $3 / 4$ & 185 & 49.7 \\
\hline & One cup and above & 176 & 47.3 \\
\hline \multirow[t]{2}{*}{ Breast feeding } & Currently/ optimum & 246 & 66.1 \\
\hline & Stop or never & 126 & 33.9 \\
\hline \multirow[t]{2}{*}{ Consuming sweaty food more } & Yes & 59 & 15.9 \\
\hline & No & 311 & 84.1 \\
\hline \multirow[t]{2}{*}{ Snuck between meal } & Yes & 309 & 83.1 \\
\hline & No & 63 & 16.9 \\
\hline \multirow[t]{2}{*}{ Eating on separate dish } & Yes & 239 & 64.2 \\
\hline & No & 133 & 35.8 \\
\hline \multirow[t]{2}{*}{ Source food most } & Industrial made & 133 & 35.8 \\
\hline & Home prepared & 239 & 64.2 \\
\hline \multirow[t]{2}{*}{ Who feed } & Mother & 246 & 66.1 \\
\hline & Caregiver & 126 & 33.9 \\
\hline
\end{tabular}

Table 5: Hygiene and environment-related factors of children age 6-59 months attend health service attend IMNCl at Bole sub-city selected health centers, Addis Ababa, Ethiopia, 2021. 


\begin{tabular}{llll} 
Variables & Alternatives & Frequency & Percent \\
\hline Hand washing with soap & Yes & 127 & 34.1 \\
\cline { 2 - 4 } & No & 245 & 65.9 \\
\hline \multirow{2}{*}{ Fresh food/not delayed } & Yes & 339 & 91.1 \\
\cline { 2 - 4 } & No & 33 & 8.9 \\
\hline Type of latrine & Standardized & 366 & 98.4 \\
\cline { 2 - 4 } & Not standardized & 6 & 1.6 \\
\hline
\end{tabular}

Table 6: Factors associated with nutritional status of children age 6-59 months attend IMNCI at Bole subcity selected health centers, Addis Ababa, Ethiopia, 2021.

Overnutrition

\begin{tabular}{|c|c|c|c|c|}
\hline Variables & Alternatives & $\begin{array}{l}\text { Crude OR at } 95 \% \\
\mathrm{Cl}\end{array}$ & AOR at $95 \% \mathrm{Cl}$ & $\begin{array}{l}\mathrm{p}- \\
\text { value }\end{array}$ \\
\hline \multirow[t]{2}{*}{ Obese/overweight mother } & Yes & $22.68(6.43-80.00)$ & $9.13(1.05-79.79)$ & 0.045 \\
\hline & No & 1 & 1 & \\
\hline \multicolumn{5}{|l|}{ Undernutrition } \\
\hline \multirow{2}{*}{$\begin{array}{l}\text { Having counselling or } \\
\text { information }\end{array}$} & Yes & 1 & 1 & \\
\hline & No & & $\begin{array}{l}18.37(4.06- \\
83.08)\end{array}$ & 0.000 \\
\hline \multirow[t]{2}{*}{ Who feed } & caregiver & $15.27(8.74-26.7)$ & $6.43(1.11-37.43)$ & 0.038 \\
\hline & Mother & & 1 & \\
\hline \multirow[t]{2}{*}{ Growth monitoring } & Yes & $0.89(0.62-1.73)$ & $0.5(0.26-0.98)$ & 0.044 \\
\hline & No & 1 & 1 & \\
\hline
\end{tabular}

\section{Figures}




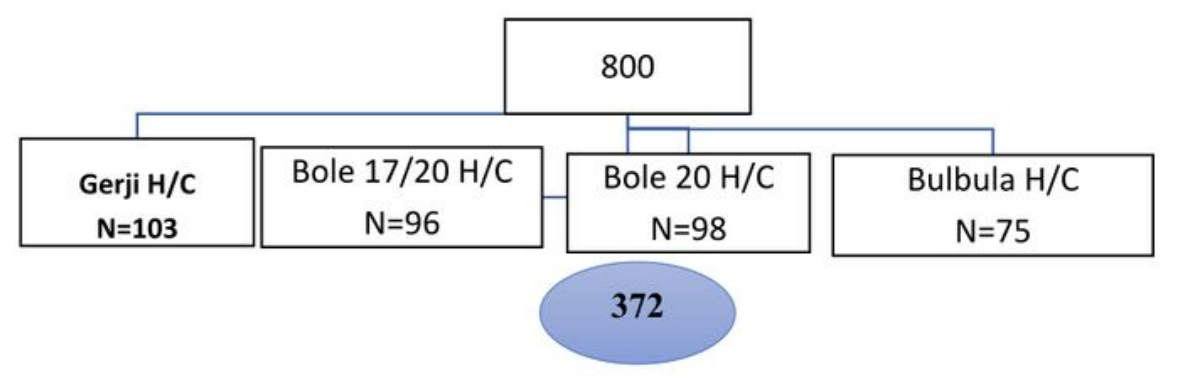

\section{Figure 1}

Hierarch of sampling of children age 6-59 months attend health service at Bole sub-city health facility, Addis Ababa Ethiopia, 2021 


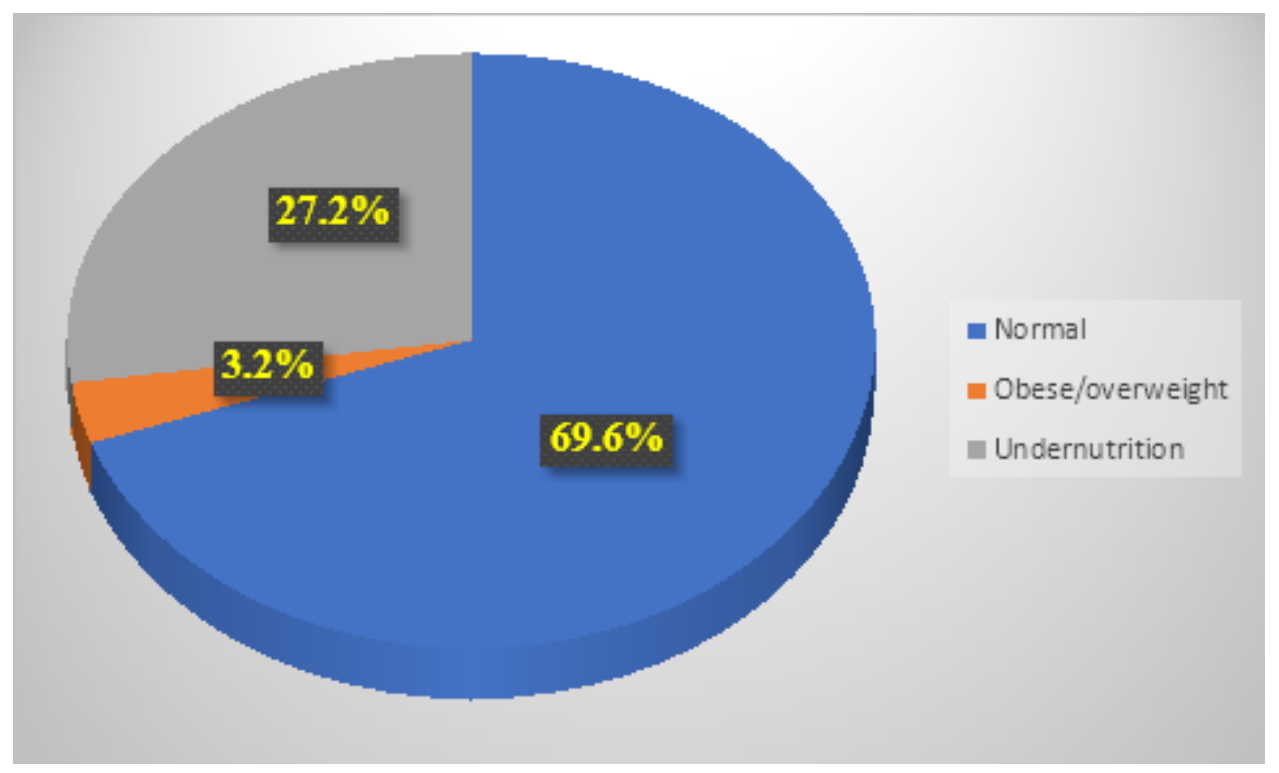

Figure 2

Overall magnitude of nutritional status among children age 6-59 months attend IMNCl at Bole sub-city selected health centers, Addis Ababa, Ethiopia, 2021. 